\title{
Two Cases of Congenital Vallecular Cyst with Respiratory Distress and Feeding Problems in Young Infant
}

\author{
Dong Eun Kim ${ }^{1}$, Eun Ha Kim ${ }^{2}$, Hye Ra Jung ${ }^{3}$ and Byung Hoon Ahn ${ }^{1}$ \\ ${ }^{1}$ Departments of Otorhinolaryngology, ${ }^{2}$ Pediatrics, ${ }^{3}$ Pathology, College of Medicine, Keimyung University, Daegu, Korea
}

\author{
기도폐색과 수유장애를 동반한 영아의 선천성 후두개곡 낭종 2예 \\ 김동은 ${ }^{1} \cdot$ 김은하 $^{2} \cdot$ 정혜라 ${ }^{3} \cdot$ 안병훈 $^{1}$

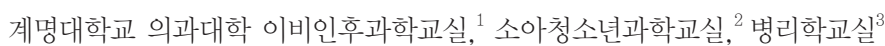

\author{
Received March 9, 2011 \\ Revised April 22, 2011 \\ Accepted April 27, 2011 \\ Address for correspondence \\ Dong Eun Kim, MD \\ Department of Otorhinolaryngology, \\ College of Medicine, \\ Keimyung University, \\ 56 Dalseong-ro, Jung-gu, \\ Daegu 700-712, Korea \\ Tel $+82-53-250-7757$ \\ Fax $+82-53-256-0325$ \\ E-mail entkde@dsmc.or.kr
}

Congenital vallecular cyst (VC) is a rare cause of stridor and respiratory distress in neonates and infants. Due to the anatomical location of the cyst, an infant with a VC is at risk of lifethreatening upper airway obstruction and eventual death. The cyst sits in the vallecular space and can cause significant retroflexion of the epiglottis. It may also present with feeding problems resulting in failure to grow. Endoscopic laryngoscopy is necessary to visualize it and marsupialization of the cyst is the preferred treatment. We present 2 successfully treated cases of congenital VC in young infants with symptoms of upper respiratory obstruction and feeding problems.

Korean J Otorhinolaryngol-Head Neck Surg 2011;54:646-9
서 론

선천성 후두개곡 낭종은 신생아나 영아기에 드문 질환이 다.) 성인에서 후두개곡 낭종이 발생하는 경우 대부분 별다른 증상이 없으나 신생아나 영아는 기도가 좁기 때문에 심각한 상기도 폐쇄를 초래할 수 있으며, 심지어 사망에 이르게 할 수 도 있다. ${ }^{2)}$ 또한 낭종이 후두개를 후방으로 전위시켜 정상적 인 연하운동을 어렵게 해 수유장애가 초래되고 이는 영양결핍 등 영아기의 발달에 심각한 영향을 줄 수 있다. ${ }^{3)}$ 따라서 다른 질환들과 선천성 후두개곡 낭종을 조기에 감별하고 적절한 치료를 신속하게 시행하는 것이 중요하다. 영아기의 후두개곡 낭종은 내시경을 이용해 관찰할 수 있으며 낭종에 대한 조대 술이 치료법으로 받아들여지고 있다.") 저자들은 낭종에 의한 상기도 폐쇄 증상과 수유장애를 동반한 출생 후 4주와 6주 된 영아를 수술을 통해 치료하였기에 문헌 고찰과 함께 보고 하는 바이다.

\section{증 례}

증 례 1

출생 직후부터 호흡시 경미한 천명음이 있었던 생후 6주된 남아가 3주 전부터 심해진 천명음과 수유장애를 호소하며 내 원하였다. 태생력상 특이사항은 없었고, 40 주 3일 만에 정상 적으로 출생하였다. 출생 당시 다른 이상 소견은 없었으나 호 흡시 천명음과 흥부 함몰 소견을 보였다. 수유시에는 반복되 는 기침과 질식 현상을 보여 출생 후 주수에 따른 정상적인 양의 수유가 불가능하였다. 출생시 $3.1 \mathrm{~kg}$ 이던 체중이 생 후 3 주에 $2.8 \mathrm{~kg}$ 으로 줄었고, 내원 당시에는 $3.7 \mathrm{~kg}$ 으로 소아 발 육 표준치에 미달되었다. 내원 당시 시행한 흉부 청진에서 천 명음이 들렸으며, 반복되는 흥부 함몰을 관찰할 수 있었다. 이러한 현상은 앙와위에서 더 심해졌다. 굴곡형 섬유광시 후 두경을 통해 단일한 낭종이 설기저부에 위치해 후두개를 후 방으로 밀고 있는 것을 확인하였다(Fig. 1). 경부 자기공명영 상에서는 $1.1 \times 1.0 \mathrm{~cm}$ 크기의 경계가 분명한 원형의 낭종성 
병변이 후두개곡 부위에서 관찰되었는데, $\mathrm{T} 1$ 강조 영상에서 는 저신호 강도, T2 강조 영상에서는 밝은 고신호 강도를 보 였다(Fig. 2). 후두개곡 낭종 또는 갑상설관 낭종 의심하에 전

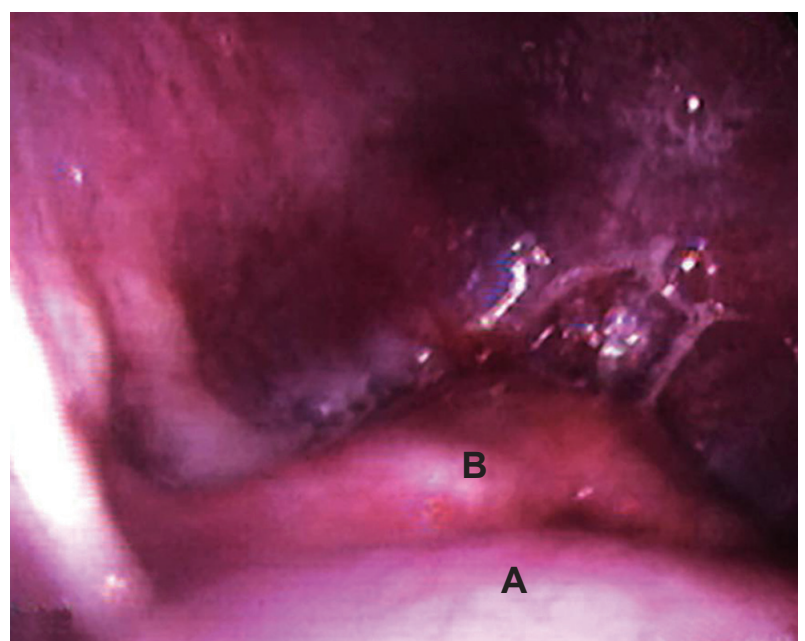

Fig. 1. Case 1. Preoperative flexible fiberoptic laryngoscopic view showing cystic mass located at the vallecular space $(A)$ pushing the epiglottis posteriorly $(\mathrm{B})$.
신마취를 통한 낭종에 대한 조대술을 시행하였다. 후두경을 삽입하고 낭종을 확인한 후 낭종 내 저류액을 일부 흡인하자 점액성 분비물이 배출되었다. 낭종의 부피가 줄어들자 기시부 위가 후두개곡임을 확인할 수 있었다. 미세 현미경 시야에서 후두 미세 수술용 겸자를 이용하여 낭종벽을 제거하고, 전기 소작기를 이용하여 기저부를 소작하였다. 조직 검사상 중증 편평 상피 세포로 구성된 낭종의 표면을 확인할 수 있었으나 갑상선 낭포 등은 보이지 않았다(Fig. 3). 수술 직후부터 천명 음이 들리지 않았고, 흉부 함몰도 관찰되지 않았다. 수술 후 에는 수유시 질식 현상을 보이지 않아 정상적인 양의 수유가 가능하였다. 환아는 수술 후 빠른 체중 증가를 보였는데 수술 후 1 개월째 $4.7 \mathrm{~kg}$, 수술 후 3 개월째 $7.3 \mathrm{~kg}$ 으로 소아 발육 표 준치에 맞게 정상적인 성장을 보였다. 수술 후 5일째 퇴원하였 으며, 추적 관찰을 위해 술 후 6 개월째 시행한 굴곡형 후두경 검사상 낭종의 재발 소견은 보이지 않았다.

\section{증 례 2}

생후 4주된 여아가 3일 전부터 악화 된 수면시 간헐적인 무

Fig. 2. Case 1. Sagittal magnetic resonance imaging, (A) T1-weighted, (B) T-2 weighted demonstrating a well-defined, round, fluid filled mass located at the base of tongue deforming the epiglottis (arrow).
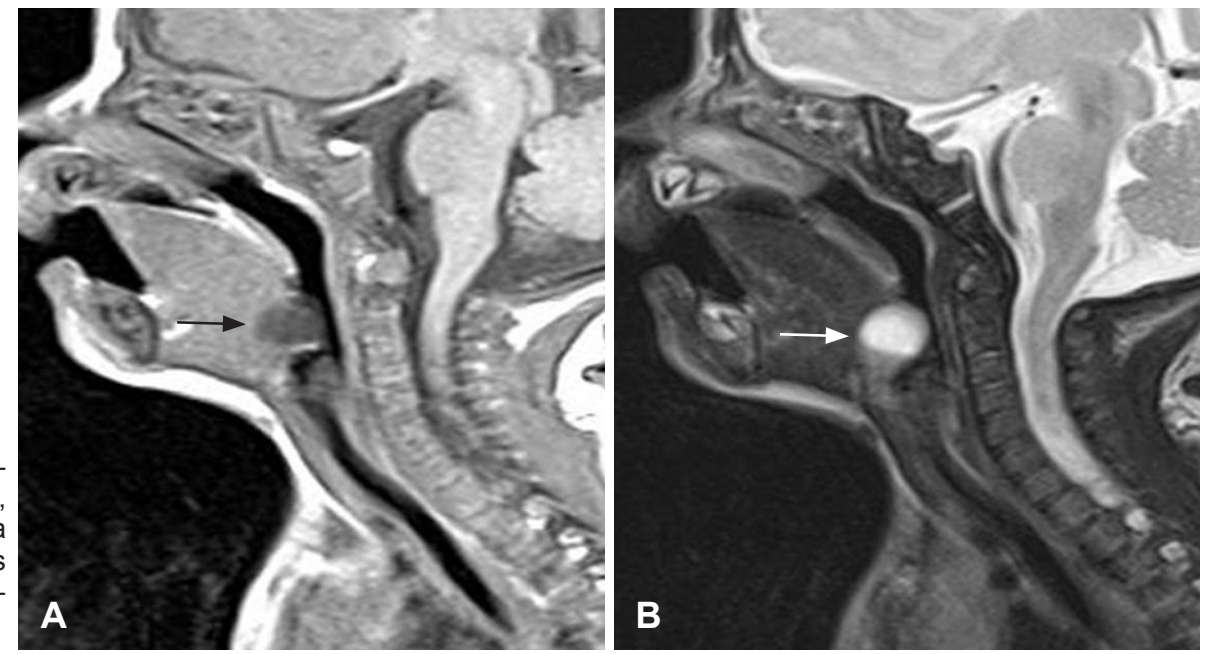

Fig. 3. Case 1. The histologic analysis showing attenuated squamous epithelium of the cyst wall [(A) Hematoxylin \& Eosin, $\times 100,(B) \times 400]$.
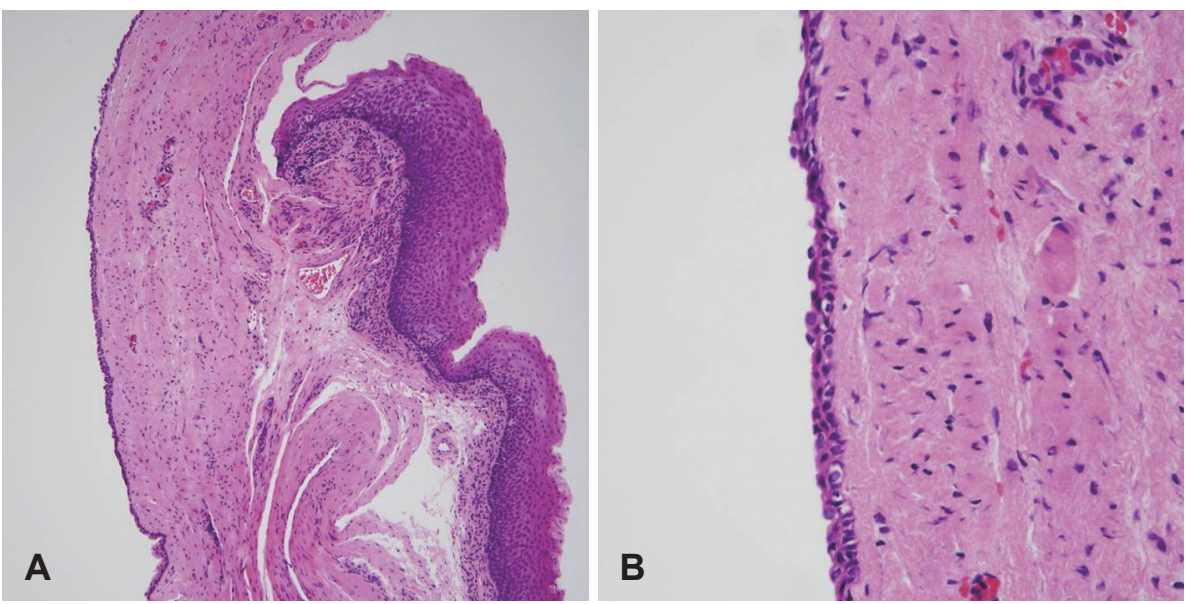
호흡과 수유장애를 주소로 본원 소아과로 입원하여 구위관 을 통해 수유를 하는 상태로 본과로 의뢰되었다. 태생력상 특 이 소견은 없었으며, 38주 4일 만에 정상 분만을 통해 출생하 였다. 출생 당시 다른 특이 소견은 없었으나 호흡시 흥부 함 몰과 약한 천명음이 있었다. 그러나 출생 후 1 주부터는 호흡 시 흥부 함몰이 심해졌으며 수유시 기침과 구토 그리고 심한 질식 현상 보이면서 청색증이 나타나 정상적인 수유가 불가 능하였다. 출생시 $3.2 \mathrm{~kg}$ 이던 체중이 생후 4주였던 내원 당시 에 $3.8 \mathrm{~kg}$ 이었다. 흥부 청진을 통해 천명음을 들을 수 있었고, 흡기시 반복되는 흥부 함몰을 관찰할 수 있었다. 편측으로 누 우면 증상이 완화되었지만 앙와위에서 증상이 심해졌다. 단 일한 낭종이 설기저부와 후두개 전방에 위치하면서 후두개를 후방으로 밀고 있는 것을 굴곡형 후두 내시경을 통해 확인하 였다. 내원 당시 시행한 컴퓨터단층촬영영상에서 $2.0 \times 2.0 \mathrm{~cm}$ 크기의 경계가 분명한 원형의 저음영 병변이 설기저부와 후두
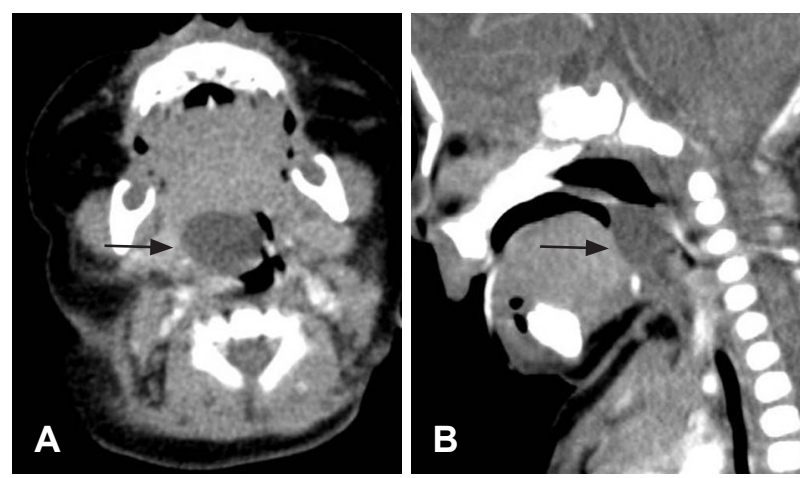

Fig. 4. Case 2. Contrast enhanced CT scans of the neck. Axial scan shows $2.0 \times 2.0 \mathrm{~cm}$ sized, hypodense lesion at the base of tongue (arrow)(A). Sagittal scan shows that well-defined, round, non-enhancing cystic mass arising from vallecular space (arrow)(B).
개곡 부위에서 관찰되었다(Fig. 4). 전신마취 하 낭종에 대한 조대술을 시행하였는데 낭종에 절개를 가하자 다량의 맑은 점액성 분비물이 배출되었다. 낭종의 부피가 줄어든 후 기시 부위가 후두개곡임을 확인할 수 있었다. 조직 검사상 중증 편 평 상피 세포로 구성된 낭종으로 판명되었다. 수술 직후부터 무호흡 증상은 보이지 않았으며 흥부 함몰도 관찰되지 않았 다. 구위관은 수술 후 1 일째 제거하였고, 수유시 수술 전에 보 였던 질식 현상이 나타나지 않아 정상적인 수유가 가능하였 다. 환아는 수술 후 빠른 체중 증가를 보였는데 수술 후 1 개 월째 $6.0 \mathrm{~kg}$ 으로 영아의 발달 단계상 정상 체중을 보였다. 수 술 5일 째 시행한 측경부 $\mathrm{X}$-선 검사상 술 전 관찰되던 후두개 곡 부위의 방사선 불투과성 병변은 보이지 않았다(Fig. 5). 술 후 5일째 퇴원하였으며, 수술 후 3 개월째 추적 관찰을 위해 시행한 굴곡형 후두경 검사상 낭종의 재발 소견은 보이지 않 았다.

\section{고 찰}

후두개곡 낭종은 후두개의 설부면에서 기시하는 다양한 크기의 단발성 낭종으로 신생아나 영아기에 발견되는 경우는 매우 드물다. ${ }^{1,3)}$ 국내에서 신생아나 영아를 대상으로 진행된 연구는 드물며 8년간 성인을 대상으로 한 연구 결과 34예의 후두개 낭종 중 후두개곡 낭종은 5예에 불과했다. ${ }^{5)}$ 이처럼 드 문 후두개곡 낭종이지만 신생아나 영아 시기에는 기도 폐쇄 로 인한 급사의 가능성과 수유장애로 인한 영양결핍과 성장 장애의 가능성이 있어 조기 진단과 치료가 중요하다. ${ }^{2)}$ 후두 낭 종은 1881년 Abicombie에 의해 처음 기술되었는데 소아에서
Fig. 5. Case 2. Before marsupialization: lateral neck radiograph shows a radiopaque mass (arrow) at the vallecular space $(A)$. Follow-up lateral neck radiograph 5 days after marsupialization shows improvement of radio opacities at the vallecular space (arrow)(B).
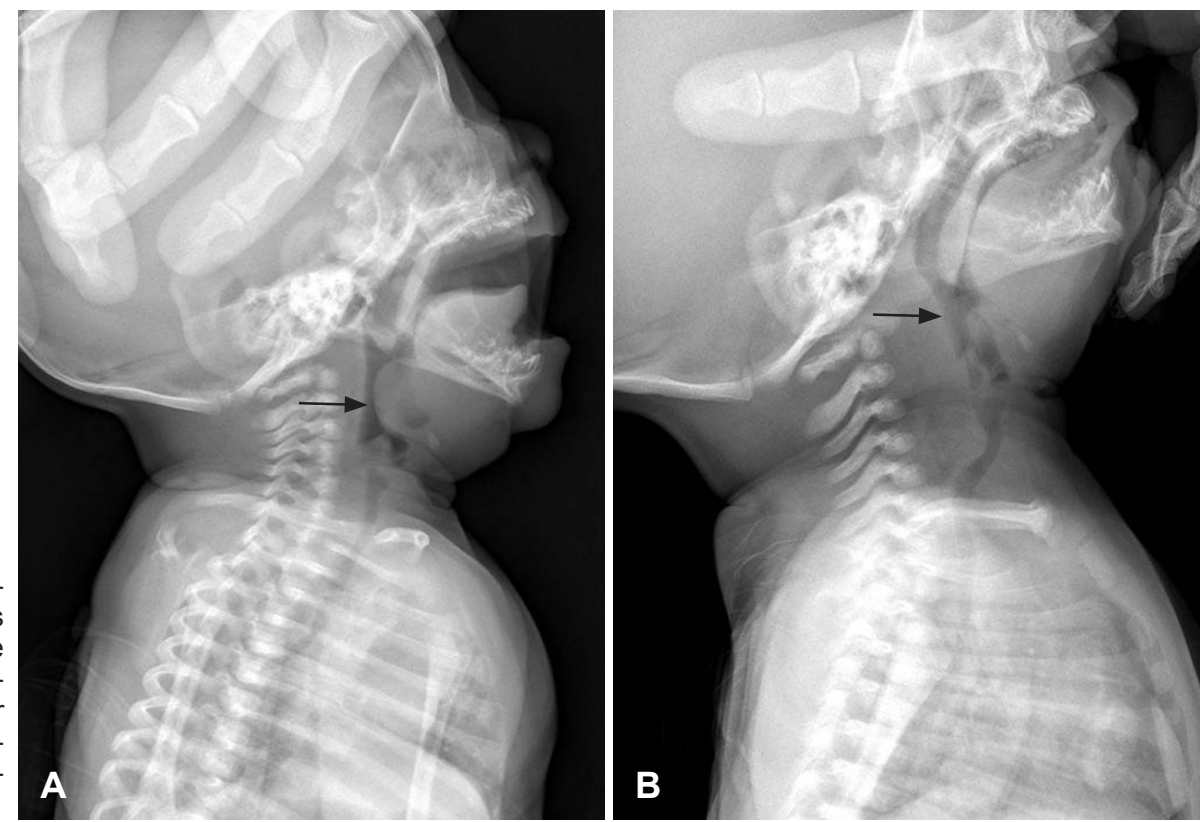
발견되는 후두 낭종 중에는 피열후두개 낭종이 가장 흔하며 그 다음으로 후두개곡 낭종, 상후두 낭종 순이다.1) DeSanto 등은 낭종의 발생 위치와 크기 그리고 점막과의 관계를 분 석하여 관상낭종(ductal cyst)과 소낭낭종(sacular cyst)으로 분류하였다. 이러한 선천성 낭종은 점액선 배출관의 폐쇄나 선천적인 기형에 의해 주로 발생하는 것으로 알려져 있다.1) 선 천성 후두개곡 낭종을 가진 대부분의 신생아와 영아들은 출 생 초기부터 상기도 폐쇄 증상을 보이는데 흡기시 천명이 주 로 관찰된다. 아울러 흥부함몰, 간헐적인 무호흡이 나타나는 데 주로 앙와위에서 심해지는 양상을 보인다. ${ }^{2}$ 또한 낭종의 해 부학적인 위치 때문에 수유장애가 동반되는데 낭종이 후두 개를 후방으로 전위시키면서 설기저부의 정상적인 연하 운동 을 방해하기 때문이다. ${ }^{3)}$ 심한 경우 수유시 청색증이 나타나 정 상적인 수유가 이루어지지 못한다. 신생아가 영아기에 수유장 애로 정상적인 체중 증가가 어렵게 되면 영양 결핍에 따른 성 장 장애가 초래되고 다른 합병증 유발의 위험도 커지기 때문 에 빠른 진단과 치료가 필요하다. ${ }^{7)}$

선천성 후두개곡 낭종은 내시경을 이용한 관찰과 영상학적 검사를 통해 진단할 수 있다. 낭종의 확인은 주로 굴곡형 섬 유광시 후두경(flexible fiberoptic laryngoscopy) 검사를 이 용한다. ${ }^{8)}$ 그러나 설기저부에 발생하는 낭종 형태의 병변은 다 양하기 때문에 갑상설관 낭종, 유피낭종, 설갑상선, 혈관종, 림 프관종 등에 대한 감별진단이 필요하다. 컴퓨터단층촬영이나 자기공명영상, 경부 측면 $\mathrm{X}$-선 검사 등이 감별진단에 도움 이 된다. 후두개곡 낭종은 컴퓨터단층촬영 영상에서 낭종 내 에 균일한 저음영이 나타나는데 이는 조영 증강되는 설갑상 선과 감별된다. 자기공명영상에서는 $\mathrm{T} 1$ 강조 영상에서 저신 호, T2 강조 영상에서 고신호가 나타난다." ${ }^{9}$ Cuillier 등 ${ }^{10)}$ 은 28 주 된 태아의 선천성 후두개곡 낭종을 산전 초음파 검사로 진 단하였는데, 이러한 조기 진단은 출생 직후 발생 가능한 신생 아 호흡곤란에 대한 적절한 치료 계획을 미리 세우는 데 도움 이 된다. 영상학적으로 갑상설관 낭종과 후두개곡 낭종은 감 별이 어려우나 수술 중 종물의 기시 부위가 갑상설관이 위치 하고 있는 부위인지 관찰하여 구분할 수 있다.11) 병리학적으 로 갑상설관 낭종은 조직에서 갑상선 낭포를 관찰할 수 있지 만 후두개곡 낭종에서는 갑상선 낭포가 보이지 않고, 낭종벽 에서 중층 편평 상피세포가 주로 관찰된다. ${ }^{12)}$ 신생아나 영아기 에 발견되는 선천성 후두개곡 낭종은 수술적 치료가 원칙으 로 받아들여지고 있으며, 낭종에 대한 조대술(marsupialization)이 주로 이용된다. 미세 후두 수술용 겸자, $\mathrm{CO}_{2}$ 레이저나 전기 소작기 등을 이용하여 낭종의 상피를 충분히 제거한다.
전기 소작기는 응고 효과가 크기 때문에 지혈에 용이하다는 장점이 있다. ${ }^{13)}$ 낭종에 대해 흡인만 시행한 경우나 불충분하 게 조대술이 이루어진 경우에는 낭종의 재발 가능성이 커지 는 것으로 알려져 있다. ${ }^{14)}$

신생아나 영아에서 천명음을 초래하는 원인 중 후두개곡 낭종은 매우 드물다. 그러나 성인과 달리 해부학적으로 기도 가 좁은 시기이기 때문에 후두개곡 낭종으로 인한 급성 호흡 폐쇄의 위험성이 있다. 또한 수유장애로 인한 성장 장애도 동 반될 수 있어 조기 진단과 적절한 치료가 중요하다.

저자들은 낭종에 의한 상기도 폐쇄 증상과 수유장애를 동 반한 영아 2예를 수술을 통해 성공적으로 치료하였기에 문헌 고찰과 더불어 보고하는 바이다.

\section{REFERENCES}

1) Mitchell DB, Irwin BC, Bailey CM, Evans JN. Cysts of the infant larynx. J Laryngol Otol 1987;101(8):833-7.

2) Yao TC, Chiu CY, Wu KC, Wu LJ, Huang JL. Failure to thrive caused by the coexistence of vallecular cyst, laryngomalacia and gastroesophageal reflux in an infant. Int J Pediatr Otorhinolaryngol 2004; 68(11):1459-64

3) Brown DJ, Lefton-Greif MA, Ishman SL. Aspiration and Swallowing disorders. In: Flint PW, Haughey BH, Lund VJ, Niparko JK, Richardson MA, Robbins KT, et al. editors. Cummings OtolaryngologyHead \& Neck Surgery. $5^{\text {th }}$ ed. Philadelphia: Elsevier Mosby;2010. p.2948-55.

4) Tuncer U, Aydoğan LB, Soylu L. Vallecular cyst: a cause of failure to thrive in an infant. Int J Pediatr Otorhinolaryngol 2002;65(2):133-5.

5) Chung PS, Chung YW, Park SJ, Kim MC. A Clinicopathologic study of epiglottic and vallecular cysts. Korean J Otolaryngol-Head Neck Surg 2004;47(2):157-60.

6) DeSanto LW, Devine KD, Weiland LH. Cyst of the larynx--classification. Laryngoscope 1970;80(1):145-76.

7) Gluckman PG, Chu TW, van Hasselt CA. Neonatal vallecular cysts and failure to thrive. J Laryngol Otol 1992;106(5):448-9.

8) Tibesar RJ, Thompson DM. Apnea spells in an infant with vallecular cyst. Ann Otol Rhinol Laryngol 2003;112(9 Pt 1):821-4.

9) Gutiérrez JP, Berkowitz RG, Robertson CF. Vallecular cysts in newborns and young infants. Pediatr Pulmonol 1999;27(4):282-5.

10) Cuillier F, Samperiz S, Testud R, Fossati P. Antenatal diagnosis and management of a vallecular cyst. Ultrasound Obstet Gynecol 2002; 20(6):623-6.

11) Park CS, Kim JH, Kim SY, Cho JH. Recurrent bronchiolitis in an infant: an unusual presentation of lingual thyroglossal duct cyst. Korean J Otorhinolaryngol-Head Neck Surg 2008;51(6):581-4.

12) Messner AH. Congenital disorders of larynx. In: Cummings CW, Flint PW, Harker LA, Haughey BH, Richardson MA, Robbins KT, et al. editors. Otolarygology Head \& Neck surgery. $4^{\text {th }}$ ed. Philadelphia: Elsevier Mosby;2005. p.4223-40.

13) Lee JK. A clinical study and treatment of the cysts on epiglottis, vallecula, and tongue base. Korean J Otolaryngol-Head Neck Surg 2005; 48(5):656-9.

14) Wong KS, Li HY, Huang TS. Vallecular cyst synchronous with laryngomalacia: presentation of two cases. Otolaryngol Head Neck Surg 1995;113(5):621-4. 